Article

\title{
A Trial-Based Cost-Utility Analysis of Metastasis-Directed Therapy for Oligorecurrent Prostate Cancer
}

\author{
Elise De Bleser ${ }^{1,2, *}$, Ruben Willems ${ }^{3}{ }^{-}$, Karel Decaestecker ${ }^{1,2}$, Lieven Annemans ${ }^{3}$, \\ Aurélie De Bruycker ${ }^{4}$, Valérie Fonteyne ${ }^{2,4}$, Nicolaas Lumen ${ }^{1,2}$, Filip Ameye ${ }^{5}$, Ignace Billiet ${ }^{6}$, \\ Steven Joniau ${ }^{7}$ (D), Gert De Meerleer ${ }^{2,8,9}$, Piet Ost ${ }^{2,4,10}$ and Renée Bultijnck 2,4,10 (D) \\ 1 Department of Urology, Ghent University Hospital, 9000 Ghent, Belgium; \\ karel.decaestecker@uzgent.be (K.D.); Nicolaas.lumen@uzgent.be (N.L.) \\ 2 Department of Human Structure and Repair, Ghent University, 9000 Ghent, Belgium; \\ valerie.fonteyne@uzgent.be (V.F.); gert.demeerleer@uzleuven.be (G.D.M.); piet.ost@ugent.be (P.O.); \\ renee.bultijnck@ugent.be (R.B.) \\ 3 Department of Public Health and Primary Care, Ghent University, 9000 Ghent, Belgium; \\ ruben.willems@ugent.be (R.W.); lieven.annemans@ugent.be (L.A.) \\ 4 Department of Radiotherapy and Experimental Cancer Research, Ghent University Hospital, 9000 Ghent, \\ Belgium; aurelie.debruycker@uzgent.be \\ 5 Department of Urology, AZ Maria Middelares, 9000 Ghent, Belgium; filip.ameye@azmmsj.be \\ 6 Department of Urology, AZ Groeninge, 8500 Kortrijk, Belgium; Ignace.billiet@azgroeninge.be \\ 7 Department of Urology, UZ Leuven, 3000 Leuven, Belgium; steven.joniau@uzleuven.be \\ 8 Department of Radiotherapy, UZ Leuven, 3000 Leuven, Belgium \\ 9 Faculty of Medicine, University of Ghent, 9000 Ghent, Belgium \\ 10 Research Foundation-Flanders (FWO), 1000 Brussels, Belgium \\ * Correspondence: elise.debleser@uzgent.be; Tel.: +329-332-22-76
}

Received: 28 October 2019; Accepted: 2 January 2020; Published: 4 January 2020

\begin{abstract}
The optimal management of patients with oligorecurrent prostate cancer (PCa) is unknown. There is growing interest in metastasis-directed therapy (MDT) for this population. The objective was to assess cost-utility from a Belgian healthcare payer's perspective of MDT and delayed androgen deprivation therapy (ADT) in comparison with surveillance and delayed ADT, and with immediate ADT. A Markov decision-analytic trial-based model was developed, projecting the results over a 5 -year time horizon with one-month cycles. Clinical data were derived from the STOMP trial and literature. Treatment costs were derived from official government documents. Probabilistic sensitivity analyses showed that MDT is cost-effective compared to surveillance (ICER: €8393/quality adjusted life year (QALY)) and immediate ADT (dominant strategy). The ICER is most sensitive to utilities in the different health states and the first month MDT cost. At a willingness-to-pay threshold of $€ 40,000$ per QALY, the cost of the first month MDT should not exceed $€ 8136$ to be cost-effective compared to surveillance. The Markov-model suggests that MDT for oligorecurrent PCa is potentially cost-effective in comparison with surveillance and delayed ADT, and in comparison with immediate ADT.
\end{abstract}

Keywords: cost-utility analysis; metastasis-directed therapy; oligorecurrent; prostate cancer; oligometastasis; prostatic neoplasms; cost-effective; markov model

\section{Introduction}

Oligorecurrent prostate cancer (PCa) is hypothesized to be an intermediate state of PCa with a restricted metastatic capacity [1]. According to the European Association of Urology (EAU) guidelines, the treatment options for these patients are independent of the number of metastases and consist of 
immediate or delayed androgen-deprivation therapy (ADT) [2]. There is a growing interest in treating oligorecurrent patients with a metastasis-directed approach aiming to postpone disease progression and the need for definitive, palliative ADT. Metastasis-directed therapy (MDT) by means of surgery or radiotherapy has already been widely evaluated in several retrospective analyses [3,4]. To date, only one prospective randomized trial, the Surveillance or Metastasis-Directed Therapy for Oligometastatic Prostate Cancer Recurrence (STOMP) trial, evaluated the effect of MDT versus surveillance in PCa [5], where MDT was either performed via surgery or via stereotactic body radiotherapy (SBRT) to the metastatic lesion(s). The median ADT-free survival after MDT was 21 months $(80 \%$ confidence interval (CI): 14-29), which was better compared to 13 months (80\% CI: 12-17) for patients on surveillance with delayed ADT (HR 0.6, 80\% CI 0.4-0.9, $p=0.11$ ). Therefore, the primary aim was to assess the cost-utility of MDT (either by means of surgery or SBRT) versus surveillance in Belgium, based on the STOMP trial [5]. Secondly, since immediate ADT is described in the guidelines as well [2], as a subset of this study, immediate ADT versus MDT was investigated.

\section{Results}

\subsection{Base Case}

In the base case analysis with a 5-year time horizon and an average patient age of 68 years, total mean discounted cost and discounted QALY per patient were respectively $€ 17,088$ and 3.86 for MDT, $€ 15,673$ and 3.74 for surveillance and $€ 21,145$ and 3.41 for ADT. The discounted ICER for MDT vs. surveillance was $€ 11,374$. For MDT vs. ADT, the mean gain in discounted cost for MDT was $€ 4058$ and the mean gain in QALY was 0.45 .

\subsection{Probabilistic Sensitivity Analyses for Base Case}

MDT vs. surveillance appeared to result in an $85.9 \%$ probability of being cost-effective (Figure 1) with a mean ICER of $€ 8393 / \mathrm{QALY}$ (Figure 2A). MDT vs. ADT appeared to be cost-effective in $100 \%$ of all iterations (Figure 1) with $99 \%$ of the cases being dominant. For the simulations situated in the right upper quadrant (gain in QALY's but more expensive treatment) the mean ICER was €1065/QALY (Figure 2B). The CEAC showed that, of the three treatment options, MDT has the highest probability of being cost-effective if the WTP threshold exceeds $€ 10,000$ (Figure 3).

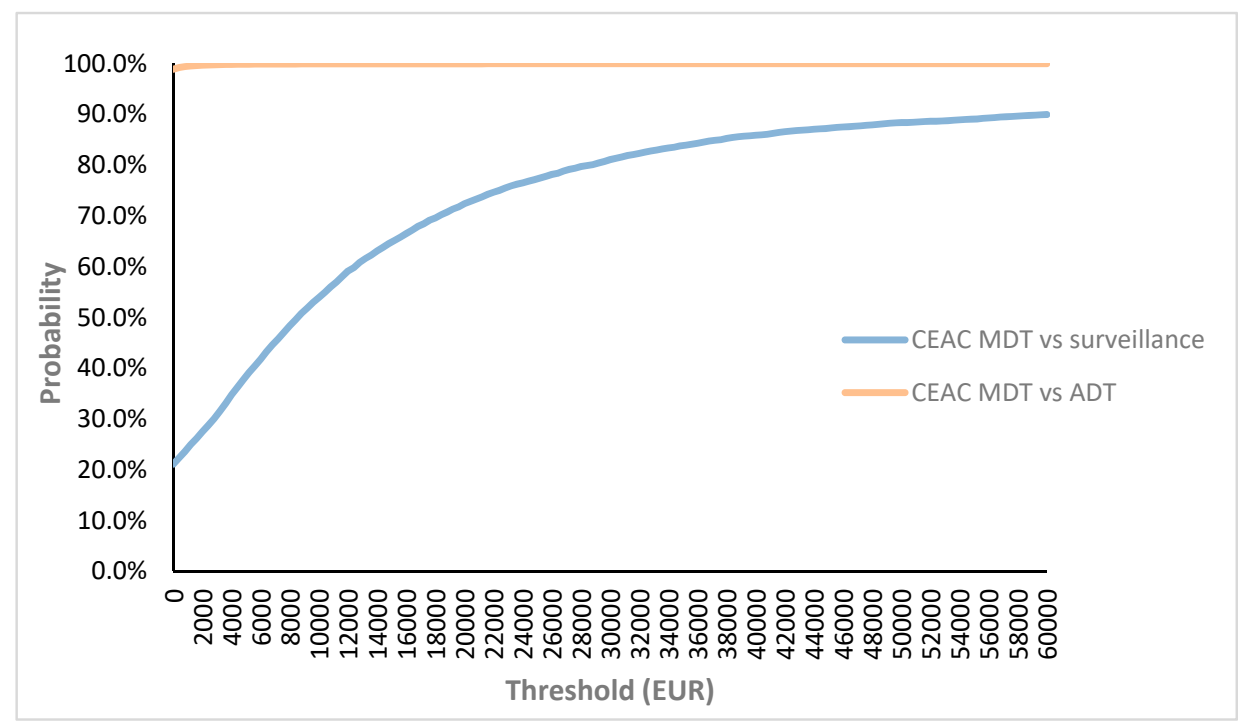

Figure 1. Probabilistic sensitivity analysis-cost-effectiveness acceptability curve. Please remark that the patients in the different groups (i.e., MDT, surveillance and ADT) entered different health states during follow-up and thus the corresponding costs and utilities of that health state were applied. Abbreviations CEAC: Cost-effectiveness acceptability curve; MDT: Metastasis-directed therapy. 


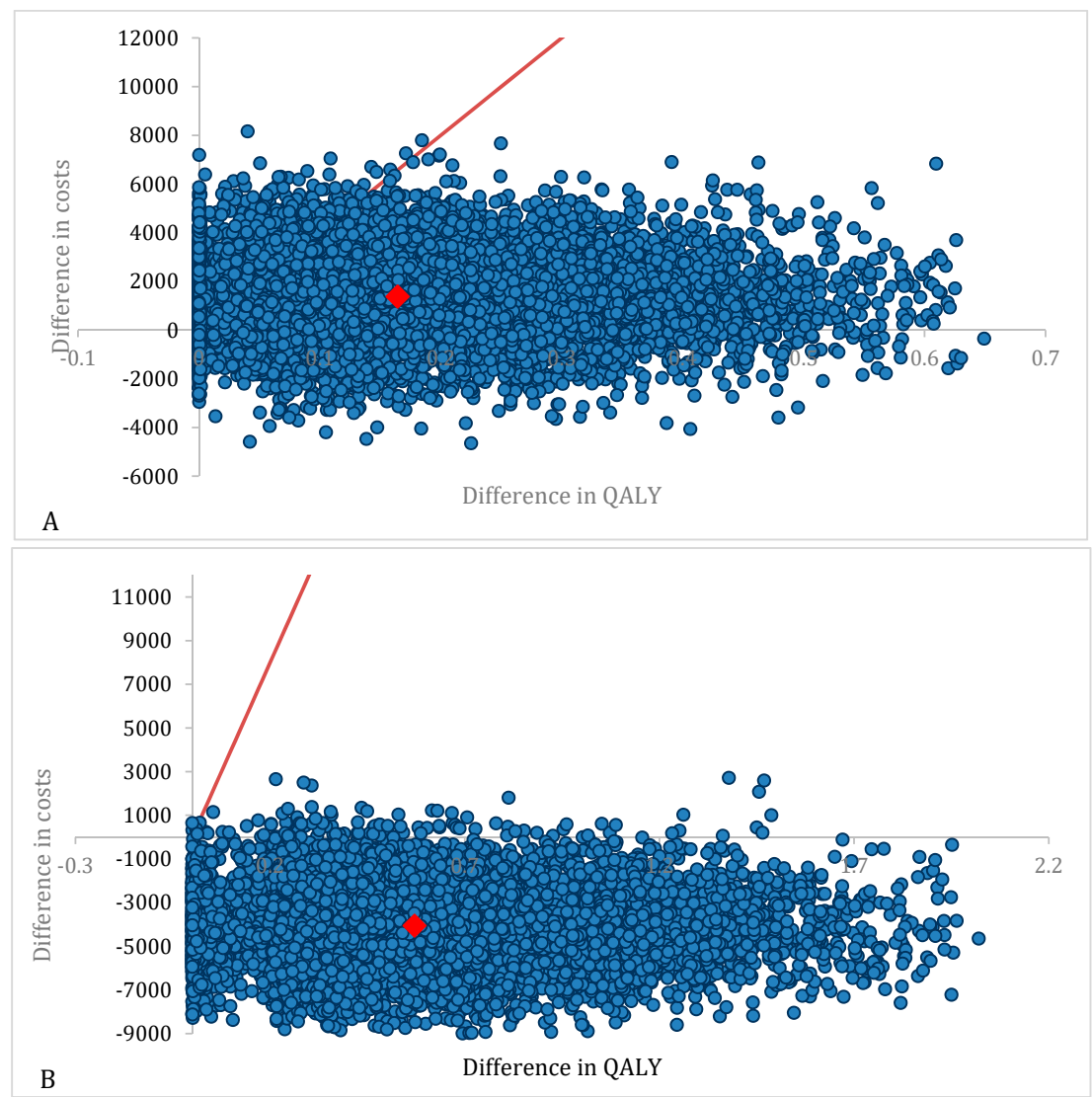

Figure 2. Graphic representation of 10,000 simulations of the cost-utility analysis of MDT versus surveillance. Every dot represents a simulation of the cost-utility analysis. The red line represents the WTP threshold. The red dot represents the mean ICER. Differences are calculated as MDT minus surveillance/ADT. (A) Cost-utility plane of MDT versus surveillance. (B) Cost-utility plane of MDT versus ADT. Please remark the different scales in Figure 1A,B. Abbreviations; MDT: Metastasis-directed therapy; QALY: Quality adjusted life years; WTP: Willingness-to-pay.

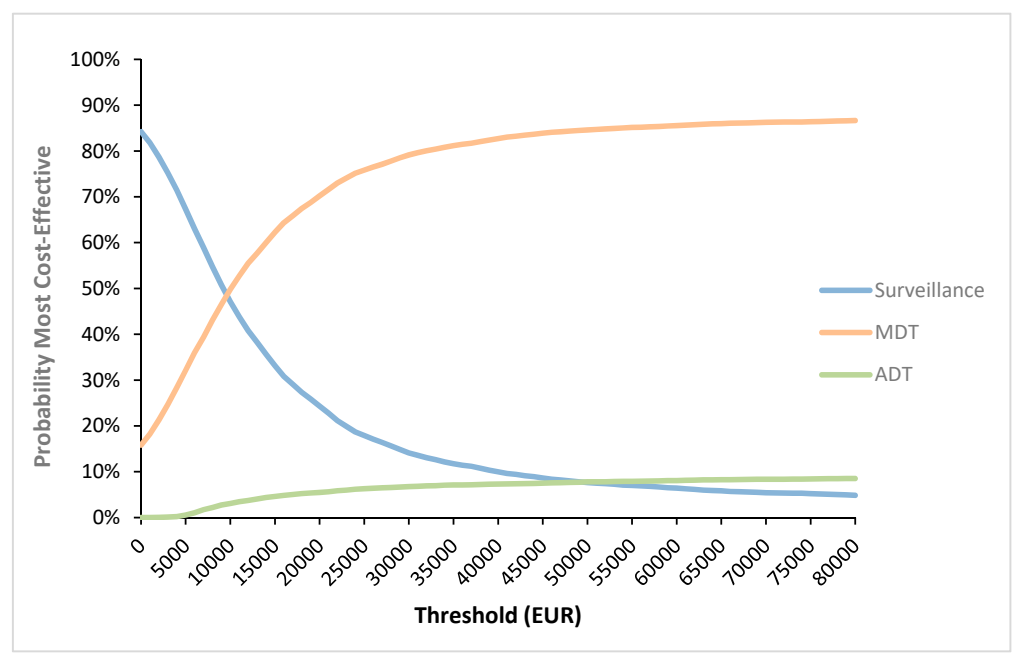

Figure 3. Multiple cost-effectiveness acceptability curve. This curve shows the most cost-effective strategy depending on the willingness-to-pay threshold. Please remark that the patients in the different groups (i.e., MDT, surveillance and ADT) entered different health states during follow-up and thus the corresponding costs and utilities of that health state were applied. ADT: Androgen-deprivation therapy; MDT: Metastasis-directed therapy. 


\subsection{One-Way Sensitivity Analysis}

Further assessing the robustness of the model, one-way deterministic sensitivity analysis was performed and graphically represented in a Tornado plot (Figure 4). The sensitivity analysis showed that the ICER was mainly sensitive to utility scores of the health states, the cost of MDT, surveillance and CRPC and new round of MDT. Nonetheless, even with the most sensitive parameters, the ICER is still cost-effective, except for a utility score of the ADT-free state of $80 \%$ of the base case value. We investigated all input parameters (Appendix A Table A1) that could influence the analysis. The parameters that had no impact on the ICER are not displayed in Figure 4.

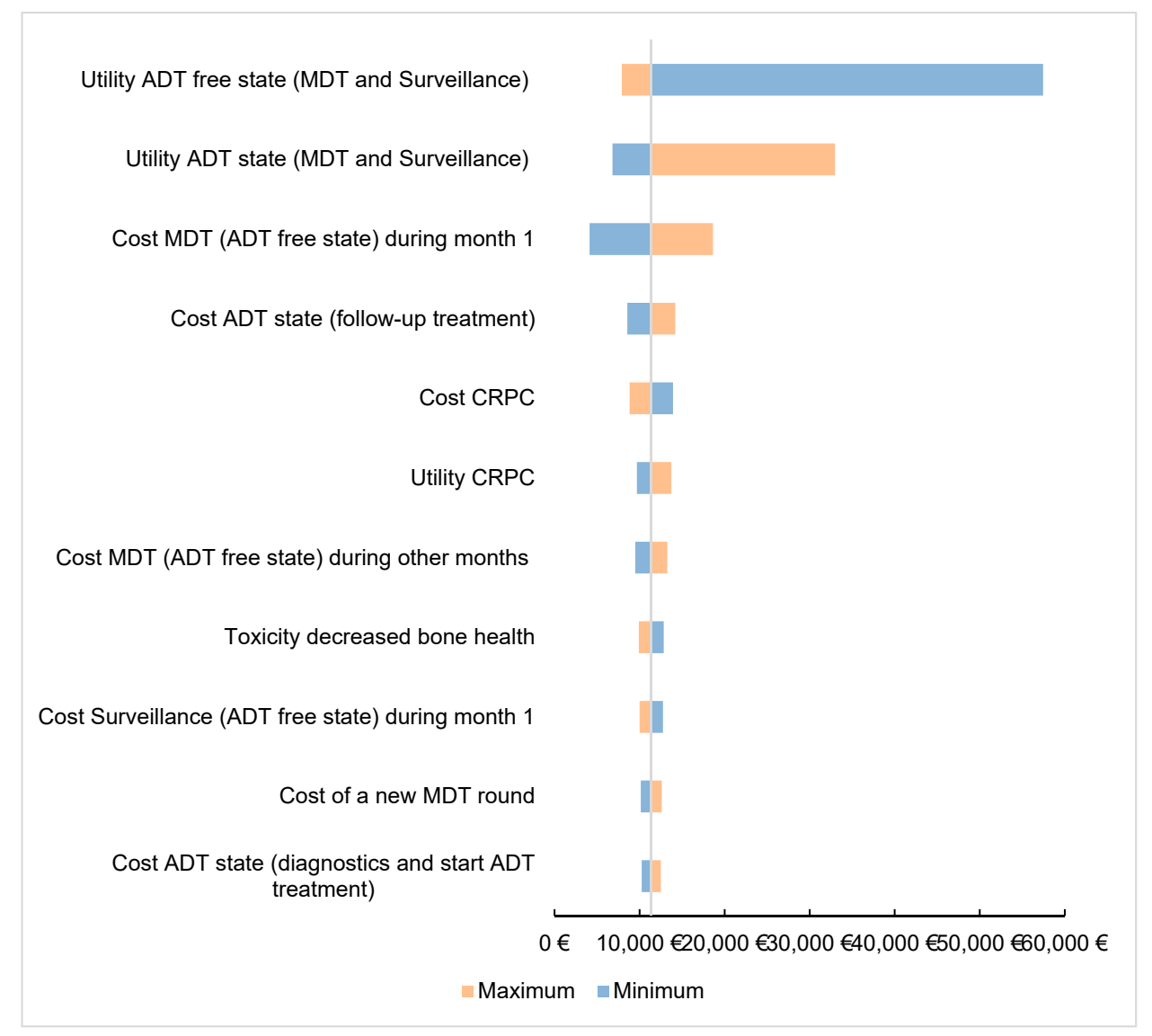

Figure 4. One-way sensitivity analysis—-tornado diagram. Tornado model showing the impact of the different variables on the ICER. In this figure, all sensitivity scores were set at $100 \%$. The figure depicts the impact on the ICER when the sensitivity score ranges from $80 \%$ to $120 \%$. ADT: Androgen-deprivation therapy; MDT: Metastasis-directed therapy.

\subsection{Scenario Analyses}

Figure 5A gives a graphic representation of the changing cost of MDT and Figure 5B of SBRT alone. As seen in Figure 5A, when comparing MDT vs. surveillance, the cost of MDT can increase up to $€ 8136$ for the ICER to remain cost-effective. When comparing MDT with ADT, this cost can even increase until $€ 26,749$ until reaching the $€ 40,000$ threshold. When looking at the SBRT cost in particular (Figure 5B), the cost of SBRT can increase up to $€ 7435$ in order to remain cost-effective compared to surveillance. Compared to ADT this cost can even increase to $€ 26,389$.

Figure 6 shows the third scenario analysis where the clinical effect of MDT was investigated. In this scenario, we gradually decreased the effect size from $100 \%$, which represents the ICER as observed in the STOMP trial, to a zero effect. MDT appeared to be a cost-effective treatment strategy as long as the prolonged ADT-free survival is at least $60 \%$ of the effect observed in the STOMP trial. 


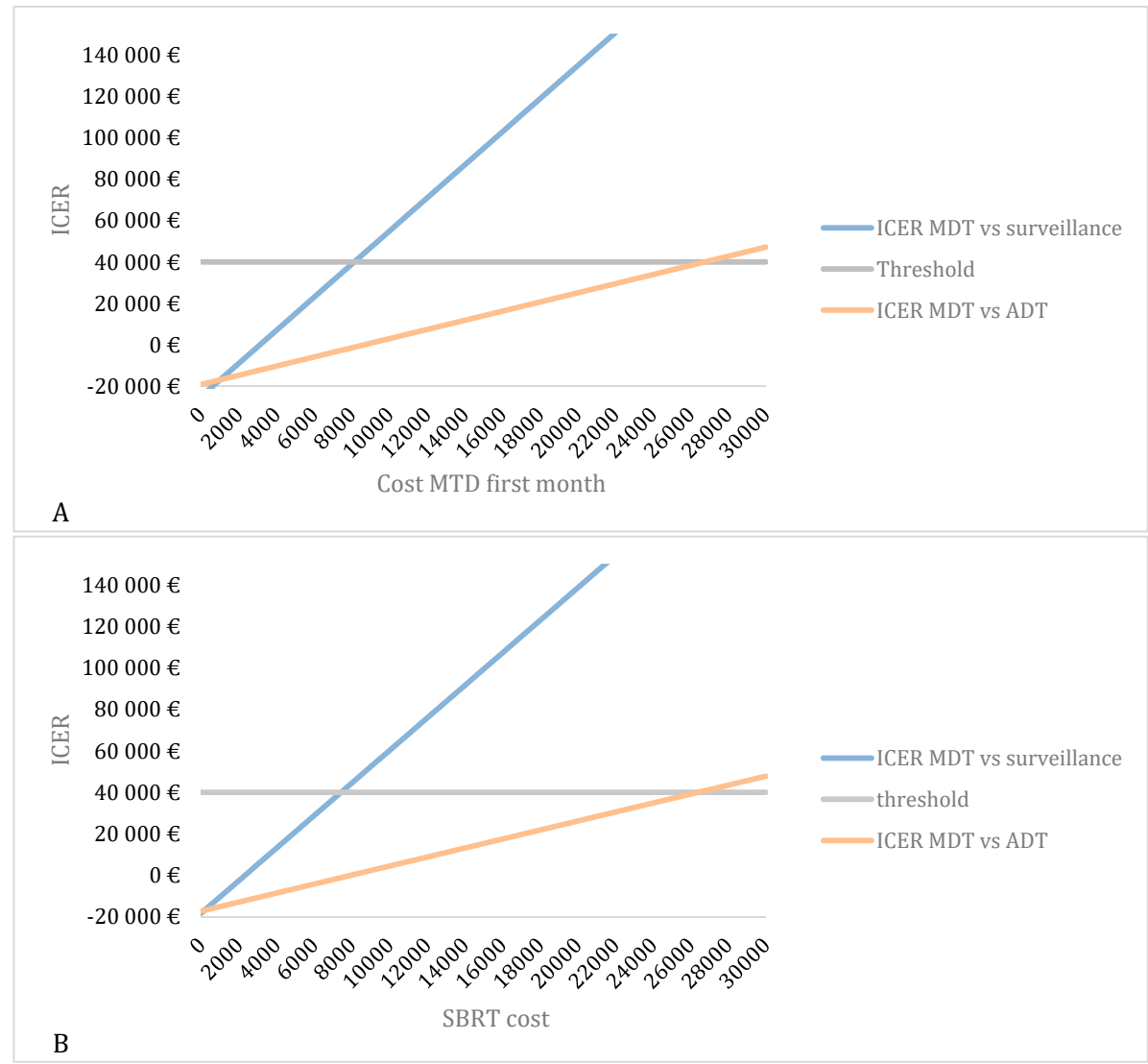

Figure 5. Scenario analyses. (A) Overall overview of the cost-utility of MDT versus surveillance or MDT versus ADT in function of the cost of MDT during the first month. (B) Overall overview of the cost-utility of MDT versus Surveillance or MDT versus ADT in function of the cost of MDT for SBRT. ADT: Androgen-deprivation therapy; ICER: Incremental cost-effectiveness ratio; MDT: Metastasis-directed therapy; SBRT: Stereotactic body radiotherapy.

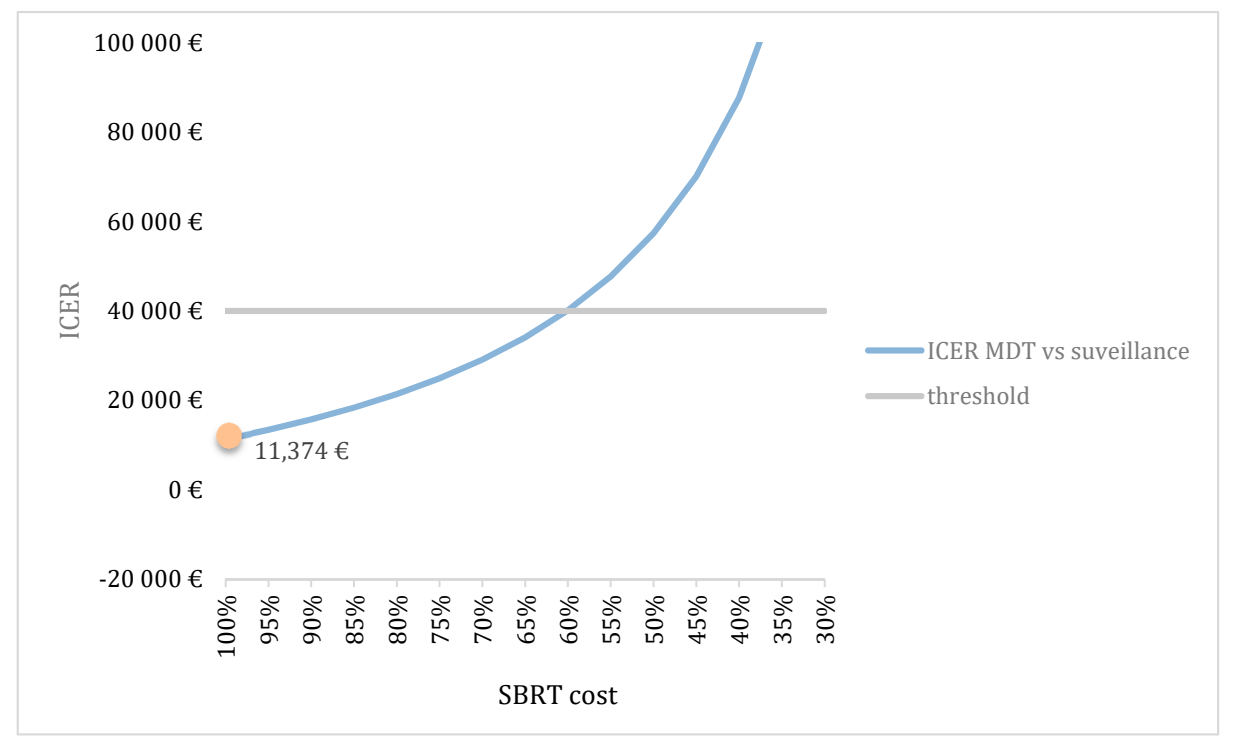

Figure 6. Scenario analysis investigating ICER in function of the effect of MDT versus surveillance. $100 \%$ is the effect as it was observed in the STOMP trial (orange dot). As seen in the figure, the ICER becomes higher when the difference in the effect of MDT versus surveillance becomes smaller. ICER: Incremental cost-effectiveness ratio; MDT: Metastasis-directed therapy. 
In a last scenario analysis we tried to investigate the influence of the standard error by varying the magnitudes of the standard error. However, varying the standard error did not impact the obtained results to a great extend (Appendix A Figure A1).

\section{Discussion}

This study investigated the cost-effectiveness of MDT in oligorecurrent PCa from a Belgian healthcare payer's perspective. Currently, the use of MDT in oligorecurrent PCa is limited with the STOMP trial being the first randomized controlled trial demonstrating a benefit in ADT-free survival of MDT [5]. Recently, Palma et al. [6] published their results on the use of palliative standard of care systemic therapy alone compared to palliative systemic therapy in combination with SBRT in different primary tumors, with PCa being the most common tumor in the SBRT group (21\%). This study showed an overall survival benefit for systemic therapy plus SBRT, however, the PCa group was too small to draw conclusions for this patient population.

To the best of our knowledge this is the first cost-effectiveness study of MDT versus surveillance, in Europe. In absence of an official WTP-threshold in Belgium, the threshold was set at €40,000/QALY [7]. Our results suggest that MDT is potentially cost-effective in oligorecurrent PCa when compared to surveillance. As there were no grade 2 or higher toxicities observed in the STOMP trial, theoretical toxicities were extracted from the literature and incorporated in the analysis. The POPSTAR trial [8] confirmed that the majority of side effects were grade 1 which were not associated with an economic impact. In this trial, only one grade 3 toxicity was observed, being a vertebral fracture. The used dose in this trial (20 Gy in one fraction) differed from that used in the STOMP trial (30 Gy in three fractions). In contrast, the toxicities reported in the recently published SABR-COMET trial [6] were of greater importance. This trial is to date the largest randomized trial comparing SBRT + standard of care versus standard of care alone, showing an improvement in overall survival and progression-free survival in the combination arm which was accompanied by a significant increase in toxicity. The most important side effects were fatigue, dyspnea and pain (grade 2 and 3) and three treatment-related deaths occurred. Nevertheless, it is important to state that the primary tumor in the SABR-COMET trial was PCa in only $21 \%$ of the patients treated with the combination. The treatment-related deaths were associated with SBRT on a lung lesion (two cases) and an adrenal metastasis (one case), two locations rather unlikely to arise from PCa [9].

In this analysis, the cost of the CRPC-state was included, however, the cost of the toxicities associated with the treatment of CRPC was not taken into account to facilitate the analysis and because the cost of CRPC was beyond the scope of this manuscript. Please remark that this is associated with an even higher benefit in real life.

Our results show the importance of the value of the WTP threshold of $€ 40,000$ per QALY. This threshold was based on the threshold for reimbursement of medicines. As seen in Figure 3, the cost-effectiveness of MDT compared to surveillance varies depending on the applied threshold and becomes cost-effective when a threshold of minimum $€ 10,000$ is used. It is important to note that this threshold varies amongst countries, also within the European Union. The WTP threshold of $€ 40,000$ per QALY is rather low compared to other countries such as the United States where a WTP threshold of $\$ 100,000-150,000$ has been suggested [10]. Another important issue are the variables included in the study that might influence cost-effectiveness. Figure 4 shows the most important factors influencing the results. As seen in the figure, the utility of the ADT-free state has the largest impact on the ICER and is the only variable making the ICER non-favorable. The lower this utility, the higher the ICER becomes. When implying a utility that is $80 \%$ of the chosen utility of 0.92 , the ICER even exceeds the $€ 40,000$ per QALY threshold. However, it is unlikely that this utility is of great influence as the probabilistic sensitivity analysis remains cost-effective in almost $86 \%$ of iterations, when all parameters are varied (Figure 2A). Although the cost of MDT could be an important influencing factor, even with a cost increase up to $120 \%$, the ICER remains cost-effective. This stresses the importance of the cost of MDT, and in particular SBRT, on the cost-effectiveness. As for the WTP threshold, the cost of SBRT 
tends to vary across countries. As seen in Figure 5B, the cost of SBRT cannot exceed $€ 7435$ for the analysis to be cost-effective.

As per EAU guidelines [2], the recommended treatment of patients presenting with recurrent PCa is immediate or delayed ADT. As the timing of ADT is still under debate, we conducted the same analysis for cost-effectiveness of MDT versus immediate ADT [11]. Since ADT is known to have an important impact on QoL and is associated with greater costs, the ICER of MDT versus ADT is even more favorable compared to MDT versus surveillance. As seen in Figure 5B, the cost of SBRT can increase up to $€ 26,389$ to remain cost-effective.

Although this analysis was based on a trial with relatively short available follow-up, MDT appears to be cost-effective compared to surveillance. Important to note is the higher utility score of the ADT-free state (0.92) compared to the ADT state (0.78) which has an important influence on the ICER (Figure 4). As ADT is associated with important side effects, affecting quality of life and higher costs, deferred start of ADT in the MDT group has an important effect on the ICER. Even more, the more patients that the start of ADT in an earlier phase, the more patients that enter the CRPC-state, leading to even higher costs.

The results of this trial suggest that MDT is a cost-effective strategy and it is economically ethical to further explore the long-term results of MDT in phase 3 trials. Besides SBRT, elective nodal radiotherapy (ENRT) is being investigated as a treatment option in these patients. The GETUG P07 trial (Salvage Radiotherapy Combined With Hormonotherapy in Oligometastatic Pelvic Node Relapses of Prostate Cancer-OLIGOPELVIS2-NCT03630666) is a prospective phase 2 trial investigating the role of ENRT as an MDT treatment strategy. The PEACE V study (Salvage Treatment of OligoRecurrent Nodal Prostate Cancer Metastases-STORM-NCT03569241) is a randomized phase 2 trial investigating PLND/SBRT versus ENRT. These trials will provide new data on the role of MDT (radiotherapy and metastasectomy) in oligorecurrent PCa and form the basis of further randomized investigations.

\section{Limitations}

Inevitably, this study was associated with several limitations. First, due to the restrictions of the trial, follow-up was rather short and currently no long-term data are available for these patients. Therefore, time horizon was set at 5 years to limit extrapolation of unknown follow-up data. Second, since this study was trial based, this gave rise to a per-study protocol patient care. We based our results on the current available international guidelines [2], where possible. However, since this is still an investigational treatment option, which is not yet included in the guidelines, no standard follow-up is available. As a consequence of the protocol-based analysis, it is assumable that the entered costs in this analysis were an overestimation. Third, patient groups of the STOMP trial were rather small. Therefore, we opted to only use the transition probabilities of the STOMP trial and use literature for toxicities and QoL data. Fourth, probabilities and health state utilities were extracted from literature and are not always well examined. Health economic evaluations of stage 2 trials are characterized with the adaption of some assumptions. It is recommended to include, for example, quality of life measurements in stage 3 and 4 clinical trials. Nevertheless, this is the first cost-effectiveness analysis of MDT versus surveillance or ADT in Europe. Even when taken these limitations into account, the ICER is situated far below the WTP threshold.

\section{Material and Methods}

\subsection{Patients and Procedures}

Patients included in the STOMP trial [5] presented with a PSA relapse and a limited number $(\leq 3)$ of nodal (N1/M1a/N1 + M1a), bone (M1b) or visceral (M1c) metastases diagnosed on choline positron emission tomography computed tomography (PET-CT). At inclusion, patients were randomly assigned to surveillance or MDT. In the surveillance group $(n=31)$, patients did not receive active treatment but were clinically re-evaluated and had a serum PSA control every 3 months, with choline 
PET-CT at specific PSA thresholds [5]. In total, 31 patients were treated by means of MDT and then followed according to the same protocol as the surveillance group. Surgery was used in five patients with nodal disease (robot-assisted pelvic lymph node dissection (PLND)) and one patient with a lung metastasis (metastasectomy). No patients were operated with an open or laparoscopic approach. All other patients in the MDT arm were treated by means of SBRT $(n=25)$ [5].

\subsection{Model Structure}

A cost-utility (CU) analysis, which compared MDT with delayed ADT vs. surveillance with delayed ADT, was conducted from a healthcare payer's perspective. A second comparison was performed between MDT and ADT. A Markov trial-based model can be consulted in Figure 7. A detailed description of the used input variables to build the analysis can be found in Appendix A Table A1 [3,5,9,12-28]. An overview of the used costs per intervention can be found in Appendix A Table A2.

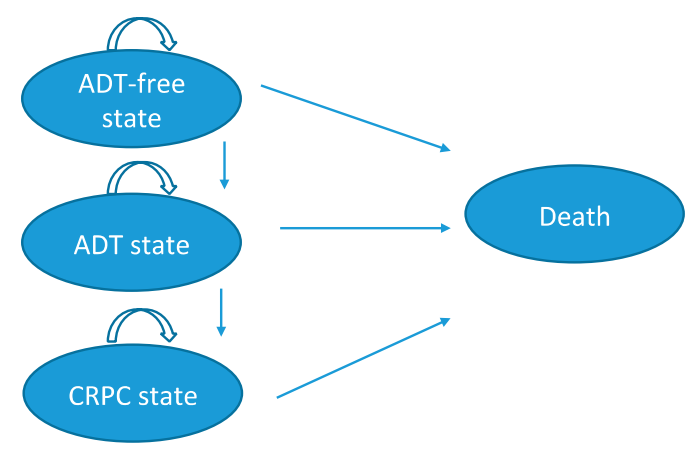

Figure 7. Markov model summarizing the state transitions (simplified model). Patients treated by MDT or surveillance enter the Markov model in the ADT-free state. Patients that are treated with immediate ADT enter the Markov model in the ADT state. Circles represents the different health states in the model. Arrows represent transitions between health states, Patients are at each health state at risk for developing side effects. ADT: Androgen-deprivation therapy; CRPC: Castration-resistant prostate cancer; MDT: Metastasis-directed therapy.

The Markov model included several health states. The first state was the ADT-free state which was defined as each cycle where patients did not require ADT. The second state was the ADT-state where ADT was initiated as a consequence of symptomatic progression, progression to polymetastatic disease (>3 metastases) or local progression of the baseline-detected metastases. The third state was castration-resistant prostate cancer (CRPC)-state where patients developed CRPC as defined by the EAU guidelines [2]. The fourth state was death from all causes. At the end of each cycle, patients could remain in the current health state or transit to another state. Possible multiple rounds of MDT were included in the analyses, based on the STOMP data. All costs associated with ADT in the MDT or surveillance group are included in the analyses. The comparator in the STOMP trial was surveillance, however, since according to the guidelines, standard of care for these patients is systemic treatment with ADT, a third treatment arm has been added [2]. Patients receiving immediate ADT entered the model in the ADT-state. The model was programmed in Microsoft ${ }^{\circledR}$ Excel.

\subsection{Time Horizon}

A 5-year time horizon with one-month cycles and half-cycle corrections has been modeled. Median follow-up in the STOMP trial was three years. An extrapolation was made up to 5 years for ADT-free survival rates. A longer time horizon is difficult to justify as there are no data available regarding the health state transition probabilities and would be associated with more uncertainty. 


\subsection{Discounting}

Future costs and benefits were discounted at a yearly rate of $3 \%$ and $1.5 \%$, respectively, as recommended for health economic evaluations in Belgium [22].

\subsection{Model Inputs}

Model parameters for our trial-based analysis were derived from the STOMP study by Ost et al. [5] and the current medical literature. Model inputs are described below, and an overview of the model inputs can be found in the Appendix A Table A1 [3,5,9,15-18,20-23,26,28].

\subsubsection{Health State Transition Probabilities}

Transition probabilities were extracted from the study by Ost et al. [5], distributed equally over six-month periods. The transition probability for ADT-state to CRPC-state was extracted from De Bruycker et al. [9].

\subsubsection{Non-Prostate Cancer-Specific Mortality}

Death due to other causes, is defined as death due to all causes other than PCa. Death from other causes was based on 2017 age-specific life tables for males in Belgium [23] and was adjusted for PCa death [24]. The risk of dying from PCa was only taken into account in the CRPC-state and was extracted from the study of De Bruycker et al. [9].

\subsection{Toxicities}

Toxicities of grade 2 or higher were considered as having a clinical and economic significant impact on the model. In the STOMP trial [5], 17\% of patients presented with grade 1 toxicity for MDT. No grade 2 or higher toxicity was observed. Based on literature [3,25-27] and expert opinion, a list of possible grade 2 or higher toxicities were used for the model MDT toxicities.

In contrast to MDT, toxicities of ADT are well described in the literature. The study by Walker et al. [28] and the international EAU-ESTRO-ESUR-SIOG guidelines on PCa [12] were used for the ADT side effects. The review by Nguyen et al. [13] was used to define the evidence-based strategies per side effect and the study by Bultijnck et al. [14] was used to incorporate the intervention rate per side effect in clinical practice. The cost of the possible side-effects of ADT was integrated in the model. The toxicity cost of next line systemic drugs in CRPC setting was not taken into account since this was beyond the scope of this study.

\subsection{Utilities}

Health outcomes were presented using QALYs to incorporate both the quantity (number of life years) and the quality (utility score) of life. A utility value ranges from 0 to 1 , where 0 represents death and 1 perfect health. Each of the health states were assigned with a utility weight corresponding with the intervention. Quality of life data was not extracted from the STOMP trial because of the limited available data. Therefore utility scores were obtained from the literature [15-18] using the cost-effectiveness analysis registry to find the individual studies [19]. As we used different sources, the chosen values were expert opinion and sensitivity analyses were performed. Utility scores differ for SBRT and surgery, therefore the ratio of SBRT and surgery usage in the STOMP trial was taken into account.

\subsection{Costs}

The healthcare payer's perspective has been applied since employment rates were expected to be negligible in the target population (average age of 68 year) and other patient costs (e.g., transportation) were excluded. The perspective included both costs for the national healthcare insurance and the patient co-payment. All costs are expressed in Euro $(€)$ and were extracted in 2018. Treatment costs 
were obtained from the Belgium National Institute for health and disability insurance (Rijksinstituut voor ziekte- en invaliditeitsverzekering, RIZIV) database [20] and cross-checked from hospital invoices from the Ghent University Hospital. Unit costs for drugs were based on the official listings of the Belgian center for pharmacotherapeutic information [21]. There are different possible ADT drugs available, however, the least expensive drug was chosen in the analysis since level 1 evidence for a better outcome with a specific type of ADT is still lacking [2] (range of ADT drug costs in Belgium per month: 63.4-141.5€) [21]. Treatment costs included the cost of diagnostics, initial treatment and follow-up costs. A full list per health state can be found in Appendix A Table A2. All calculations included the possibility of multiple rounds of SBRT, based on data of the STOMP trial [5].

\subsection{Statistical Analysis}

The main outcome was the incremental cost-effectiveness ratio (ICER), which was calculated as follows:

$$
I C E R=\frac{\text { COSTmdt }- \text { COSTsurveillance }}{* \text { QALYmdt }- \text { QALYsurveillance }}
$$
of life.

* Quality-adjusted life years (QALY) is a measure of quantity (number of life years) and the quality

A treatment strategy with an ICER less than the societal willingness-to-pay (WTP) threshold is cost-effective, and a negative ICER means that the new strategy generates more health at a lower long-term cost (i.e., dominant strategy). In Belgium, a WTP has not been formalized so the threshold is set at $€ 40,000$ per QALY. This is in line with the reimbursement threshold often cited for medications [29].

One-way sensitivity analysis was performed to identify key parameters impacting the ICER. The low and high end of each parameter were set on $80 \%$ and $120 \%$ of the deterministic value, respectively. This was to evaluate the uncertainty of the chosen analysis.

In addition, all parameters included in the one-way sensitivity analysis were varied simultaneously in a second order Monte-Carlo simulation (i.e., probabilistic sensitivity analysis). Costs were modeled using a gamma distribution, and probabilities and utilities were modeled using a beta distribution [30]. Ten thousand iterations of input parameters were randomly sampled. A maximum limit was accounted for in the probabilistic analysis with the assumption that a more progressed disease state always has a lower utility score than the previous one (e.g., CRPC-state utility cannot be higher than ADT-state utility).

In the analysis, MDT was compared with surveillance. A second analysis compared MDT with immediate ADT. For completeness, a multiple cost-effectiveness acceptability curve (CEAC) visualized the most cost-effective treatment option at varying thresholds.

Scenario analyses were conducted to determine the impact of input parameters with different scenarios. The SBRT cost and first month MDT cost were varied in two different scenarios to determine the maximum cost price for still being cost-effective at a $€ 40,000 / Q A L Y$ threshold. Furthermore, we conducted a scenario analysis to predict the cost-effectiveness in case of a non-significant difference in ADT-free survival of MDT versus surveillance. A last scenario analysis was conducted to take into account the uncertainty around the standard error of the literature, data scenario analysis was performed on these standard errors (resp. 0.05, 0.1, 0.15, 0.2 and 0.25).

\section{Conclusions}

This trial-based cost-utility study suggests that MDT is potentially cost-effective in the treatment of oligorecurrent PCa patients compared to surveillance with delayed ADT and even to immediate ADT. However, this analysis was based on the results of the STOMP trial which had a phase 2 design. Nevertheless, this study suggests a health economic advantage of MDT and supports ongoing phase III studies to confirm its efficacy. When more (follow-up) data are available, it is recommended to provide an update of the model. 
Author Contributions: Conceptualization, E.D.B., P.O. and R.B.; Data curation, E.D.B., R.W., K.D., L.A., A.D.B., V.F., N.L., F.A., I.B., S.J., G.D.M., P.O. and R.B.; Formal analysis, E.D.B., R.W., L.A., P.O. and R.B.; Investigation, E.D.B., R.W., L.A., P.O. and R.B.; Methodology, E.D.B., R.W., L.A., P.O. and R.B.; Project administration, E.D.B., P.O. and R.B.; Resources, E.D.B. and P.O.; Software, R.W. and L.A.; Supervision, P.O. and R.B.; Validation, E.D.B., R.W., L.A., P.O. and R.B.; Visualization, E.D.B., P.O. and R.B.; Writing-Original draft, E.D.B., R.W. and R.B.; Writing-Review \& editing, E.D.B., R.W., K.D., L.A., A.D.B., V.F., N.L., F.A., I.B., S.J., G.D.M., P.O. and R.B. All authors have read and agreed to the published version of the manuscript.

Funding: This research received no external funding.

Acknowledgments: E.D.B.: Travel expenses and congress sponsoring by Ferring, Astellas, Ipsen. Speaker for Astellas. R.B. is supported by a Ph.D. fellowship fundamental research of the Research Foundation-Flanders (FWO). P.O. and S.J. are senior clinical investigators of the Research Foundation-Flanders (FWO). P.O.: Institute research funding: Merck. Consultancy honoraria or advisory board (institute): Ferring, BMS, Janssen, Bayer.

Conflicts of Interest: The authors declare no conflict of interest.

\section{Appendix A}

Table A1. General overview of the model input variables.

\begin{tabular}{|c|c|c|c|c|}
\hline Inputparameter & Deterministic Value & Standard Error & Distribution & Source \\
\hline Mean age (years) & 68.15 & NA & NA & [5] \\
\hline Discount rate costs $(\%)$ & $3 \%$ & NA & NA & [22] \\
\hline $\begin{array}{c}\text { Discount rate utilities } \\
(\%)\end{array}$ & $1.5 \%$ & NA & NA & [22] \\
\hline \multicolumn{5}{|c|}{ Disease-related probabilities (\%) } \\
\hline $\begin{array}{c}\text { ADT-free survival in } \\
\text { MDT }\end{array}$ & $\begin{array}{l}6 \text { months: } 94 \% \\
12 \text { months: } 67 \% \\
18 \text { months: } 46 \% \\
24 \text { months: } 46 \%\end{array}$ & NA & NA & [5] \\
\hline $\begin{array}{l}\text { ADT-free survival in } \\
\text { surveillance }\end{array}$ & $\begin{array}{l}6 \text { months: } 85 \% \\
12 \text { months: } 56 \% \\
18 \text { months: } 32 \% \\
24 \text { months: } 23 \%\end{array}$ & NA & NA & [5] \\
\hline $\begin{array}{c}\text { Transition to CRPC state } \\
\text { from ADT state }\end{array}$ & $\begin{array}{c}6 \text { months: } 1 \% \\
12 \text { months: } 7 \% \\
18 \text { months: } 12 \% \\
24 \text { months: } 20 \% \\
30 \text { months: } 26 \% \\
36 \text { months: } 28 \% \\
42 \text { months: } 32 \% \\
48 \text { months: } 35 \%\end{array}$ & NA & NA & [9] \\
\hline \multicolumn{5}{|c|}{ Mortality risk } \\
\hline Death from other causes & $\begin{array}{c}68 \text { year: } 0.018123 \\
69 \text { year } 0.019817 \\
70 \text { years: } 0.020578 \\
71 \text { years } 0.023583 \\
72 \text { years } 0.026009\end{array}$ & NA & NA & [23] \\
\hline PCa death in CPRC state & $5.7143 \%$ & NA & NA & [9] \\
\hline
\end{tabular}


Table A1. Cont.

\begin{tabular}{|c|c|c|c|c|}
\hline Inputparameter & Deterministic Value & Standard Error & Distribution & Source \\
\hline \multicolumn{5}{|c|}{ Utilities * } \\
\hline $\begin{array}{l}\text { MDT during the first } \\
\text { month }\end{array}$ & 0.72 & 0.17 & Beta & [15] \\
\hline ADT-free state & 0.92 & 0.23 & Beta & {$[16,17]$} \\
\hline ADT state & 0.78 & 0.19 & Beta & [17] \\
\hline $\begin{array}{c}\text { CRPC state } \\
\text { (chemotherapy } \\
\text { accounted for } 30 \% \text { in this } \\
\text { state) }\end{array}$ & 0.6 & 0.15 & Beta & {$[16,18]$} \\
\hline \multicolumn{5}{|c|}{ Costs intervention $(€)$} \\
\hline $\begin{array}{l}\text { MDT cost month } 1 \\
\text { (ADT-free state) }\end{array}$ & 4549 & 1137 & Gamma & {$[20,21]$} \\
\hline $\begin{array}{l}\text { MDT cost other months } \\
\text { (ADT-free state) }\end{array}$ & 47 & 12 & Gamma & {$[20]$} \\
\hline $\begin{array}{l}\text { Surveillance cost month } \\
1 \text { (ADT-free state) }\end{array}$ & 865 & 216.3 & Gamma & [20] \\
\hline $\begin{array}{l}\text { Surveillance cost other } \\
\text { months (ADT free state) }\end{array}$ & 17 & 4.4 & Gamma & [20] \\
\hline $\begin{array}{l}\text { Cost diagnostics and } \\
\text { start ADT (ADT state) }\end{array}$ & 1266 & 317 & Gamma & {$[20,21]$} \\
\hline $\begin{array}{l}\text { Cost ADT in follow-up } \\
\text { months ADT (ADT state) }\end{array}$ & 298 & 74.7 & Gamma & {$[20,21]$} \\
\hline $\begin{array}{c}\text { CRPC costs } \\
\text { (combination of } \\
\text { diagnostics, treatment } \\
\text { and follow-up) } \\
\text { (distribution of } \\
\text { abiraterone acetate } 35 \% \text {, } \\
\text { enzalutamide } 35 \% \text { and } \\
\text { docetaxel } 30 \% \text { ) }\end{array}$ & 775 & 193 & Gamma & {$[20,21]$} \\
\hline \multicolumn{5}{|c|}{ ADT toxicities probabilities } \\
\hline Gynecomastia & $13 \%$ & NA & Beta & [28] \\
\hline Osteoporosis & $10 \%$ & NA & Beta & [28] \\
\hline Diabetes & $9 \%$ & NA & Beta & [28] \\
\hline Fatigue & $80 \%$ & NA & Beta & [28] \\
\hline Sexual dysfunction & $95 \%$ & NA & Beta & [28] \\
\hline $\begin{array}{l}\text { Reduced penile/testis } \\
\text { size }\end{array}$ & $93 \%$ & NA & Beta & [28] \\
\hline Hot flashes & $80 \%$ & NA & Beta & [28] \\
\hline Cognitive changes & $48 \%$ & NA & Beta & [28] \\
\hline Anemia & $13 \%$ & NA & Beta & [28] \\
\hline Metabolic syndrome & $55 \%$ & NA & Beta & {$[28]$} \\
\hline
\end{tabular}


Table A1. Cont.

\begin{tabular}{ccccc}
\hline Inputparameter & Deterministic Value & Standard Error & Distribution & Source \\
\hline & MDT toxicities probabilities & & \\
\hline Lymph oedema & $0.4 \%$ & 0.001 & Beta & {$[3]$} \\
\hline $\begin{array}{c}\text { Anemia needing blood } \\
\text { transfusion }\end{array}$ & $0.2 \%$ & 0.0005 & Beta & {$[3]$} \\
\hline $\begin{array}{c}\text { Symptomatic } \\
\text { lymphocoele }\end{array}$ & $5 \%$ & 0.0125 & Beta & {$[3]$} \\
\hline Neuropraxia & $0.4 \%$ & 0.001 & Beta & {$[3]$} \\
\hline Pain & $1 \%$ & 0.0025 & Beta & $\begin{array}{c}\text { Expert } \\
\text { opinion }\end{array}$ \\
\hline Diarrhea & $4 \%$ & 0.01 & Beta & {$[26]$} \\
\hline
\end{tabular}

${ }^{*}$ An average utility per health state (and thus treatment) was used, rather than a disutility per possible side effect. ADT: Androgen-deprivation therapy; CRPC: Castration-resistant prostate cancer; MDT: Metastasis-directed therapy; NA: Not applicable; PCa: Prostate cancer.

Table A2. Detailed overview of the cost.

\begin{tabular}{|c|c|c|}
\hline Cost & Specification & Cost Estimates $(€)$ \\
\hline Cost at diagnosis & $\begin{array}{l}\text { Imaging (choline PET CT, MR soft tissue and } \\
\text { MR total spine), consultation, laboratory } \\
\text { monitoring and multidisciplinary oncological } \\
\text { consultation (MOC) }\end{array}$ & $\begin{array}{c}\text { Choline PET-CT: } 747.72 \\
\text { MR: } 207.48 \\
\text { Consultation at urologist/radiation } \\
\text { oncologist: } 25.43 \\
\text { PSA laboratory: } 30.5 \\
\text { MOC: } 61.54\end{array}$ \\
\hline Initial treatment-SBRT & $\begin{array}{l}\text { Physician fees, CT-simulation, planning, } \\
\text { treatment, drugs, laboratory monitoring (with } \\
\text { calculated possibility of new SBRT round) }\end{array}$ & SBRT: 3782.24 \\
\hline Initial treatment-ADT & $\begin{array}{l}\text { We investigated the different sorts of ADT } \\
\text { (Luteinizing hormone releasing hormone } \\
\text { (LHRH)- agonist and antagonist), taken into } \\
\text { account the frequency of injection, the } \\
\text { associated consultation, etc. and decided to } \\
\text { use the drug associated with the lowest cost }\end{array}$ & $\begin{array}{l}\text { Range of costs of different ADT: } \\
63.40-141.5 \text { per month }\end{array}$ \\
\hline $\begin{array}{l}\text { Initial } \\
\text { treatment-surgery }\end{array}$ & $\begin{array}{l}\text { Physician fees, anesthetic drugs, hospital } \\
\text { admission, medication and laboratory } \\
\text { monitoring }\end{array}$ & Robot-assisted PLND: 3109.35 \\
\hline $\begin{array}{l}\text { Cost of surveillance } \\
\text { group }\end{array}$ & $\begin{array}{l}\text { Diagnostics cost, follow-up visit and } \\
\text { laboratory monitoring }\end{array}$ & $\begin{array}{c}\text { Choline PET-CT: } 747.72 \\
\text { MR: } 207.48 \\
\text { Consultation at urologist/radiation } \\
\text { oncologist: } 25.43 \\
\text { PSA laboratory: } 30.5\end{array}$ \\
\hline Treatment CRPC state & $\begin{array}{l}\text { Diagnostics costs (imaging, consultation, } \\
\text { laboratory and MOC), three possible } \\
\text { treatment strategies (abiraterone acetate (AA), } \\
\text { enzalutamide and docetaxel *), monitoring } \\
\text { costs depending on the treatment. }\end{array}$ & $\begin{array}{c}\text { CRPC first month inclusive } \\
\text { diagnostic costs and ADT: } 1165.76 \\
\text { Overall mean cost of CRPC state } \\
\text { per month: } 775.66\end{array}$ \\
\hline
\end{tabular}

Costs are expressed in Euro $(€)$ and were extracted in 2018 [20,21] * Based on expert opinion, distribution of the treatments was respectively set at 35, 35 and 30\%. AA: abiraterone acetate; ADT: Androgen-deprivation therapy; CRPC: Castration-resistant prostate cancer; MDT: Metastasis-directed therapy; NA: Not applicable; PCa: Prostate cancer; QALY: Quality-adjusted life years. 


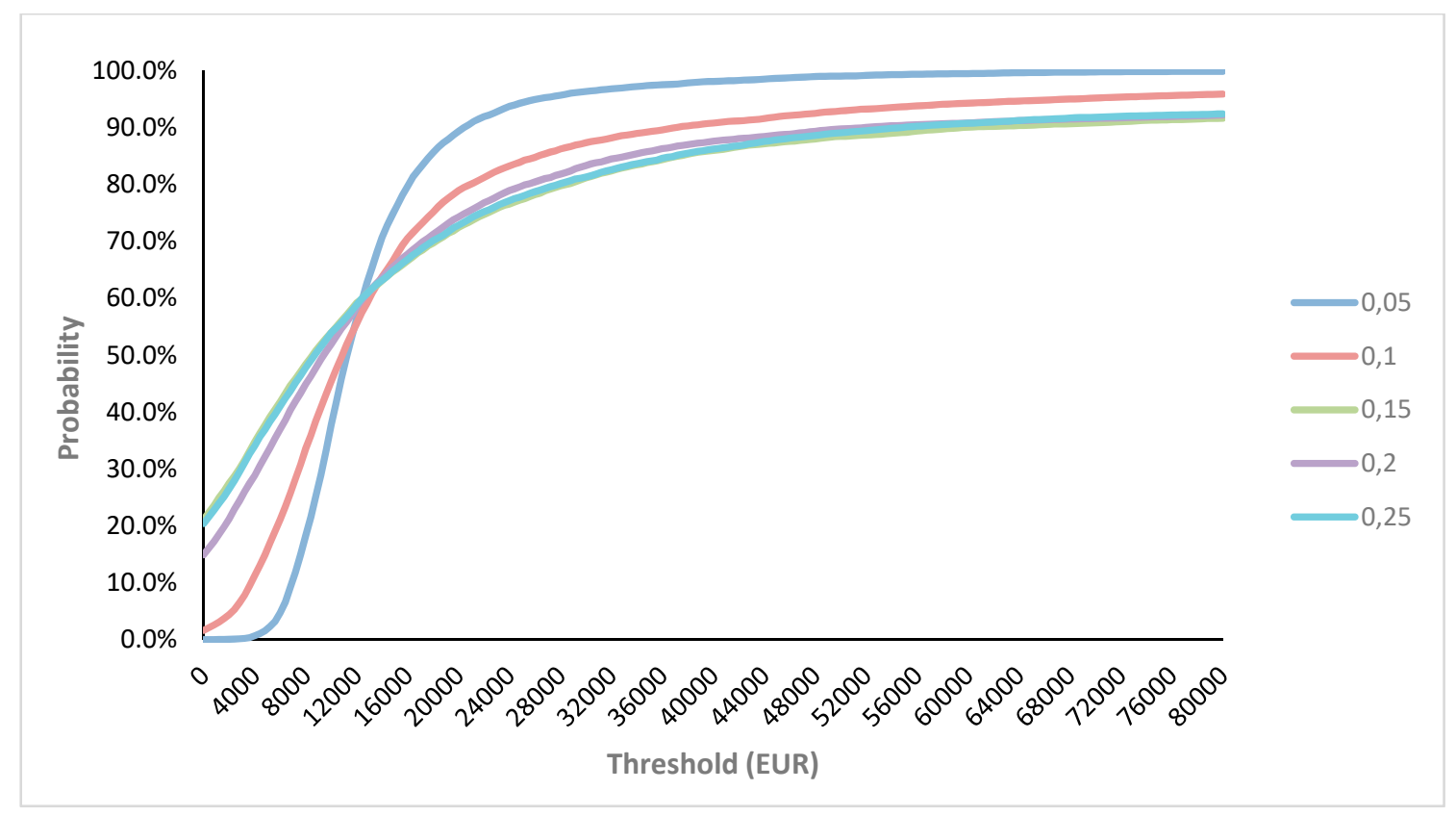

Figure A1. Cost-effectiveness acceptability curve of MDT versus surveillance. In order to evaluate the uncertainty of the input variables, the standard error of the mean was varied: mean * magnitude, with magnitude $0.05,0.1,0.15,0.20$, and 0.25 . The results were robust, with MDT versus surveillance being cost-effective at a willingness-to-pay threshold of 40,000 euro in respectively $98 \%, 90.7 \%, 85.9 \%$, $87.6 \%$, and $86.2 \%$ of the iterations. MDT: Metastasis-directed therapy.

\section{References}

1. Weichselbaum, R.R.; Hellman, S. Oligometastases Revisited. Nat. Rev. Clin. Oncol. 2011, 8, 378-382. [CrossRef] [PubMed]

2. Cornford, P.; Bellmunt, J.; Bolla, M.; Briers, E.; De Santis, M.; Gross, T.; Henry, A.M.; Joniau, S.; Lam, T.B.; Mason, M.D.; et al. EAU-ESTRO-SIOG Guidelines on Prostate Cancer. Part II: Treatment of Relapsing, Metastatic, and Castration-Resistant Prostate Cancer. Eur. Urol. 2017, 71, 630-642. [CrossRef] [PubMed]

3. Ploussard, G.; Gandaglia, G.; Borgmann, H.; de Visschere, P.; Heidegger, I.; Kretschmer, A.; Mathieu, R.; Surcel, C.; Tilki, D.; Tsaur, I.; et al. Salvage Lymph Node Dissection for Nodal Recurrent Prostate Cancer: A Systematic Review. Eur. Urol. 2018. [CrossRef] [PubMed]

4. De Bleser, E.; Tran, P.T.; Ost, P. Radiotherapy as Metastasis-Directed Therapy for Oligometastatic Prostate Cancer. Curr. Opin. Urol. 2017, 27, 587-595. [CrossRef] [PubMed]

5. Ost, P.; Reynders, D.; Decaestecker, K.; Fonteyne, V.; Lumen, N.; De Bruycker, A.; Lambert, B.; Delrue, L.; Bultijnck, R.; Claeys, T.; et al. Surveillance or Metastasis-Directed Therapy for Oligometastatic Prostate Cancer Recurrence: A Prospective, Randomized, Multicenter Phase II Trial. J. Clin. Oncol. 2018, 36, 446-453. [CrossRef]

6. Palma, D.A.; Olson, R.; Harrow, S.; Gaede, S.; Louie, A.V.; Haasbeek, C.; Mulroy, L.; Lock, M.; Rodrigues, G.B.; Yaremko, B.P.; et al. Stereotactic Ablative Radiotherapy versus Standard of Care Palliative Treatment in Patients with Oligometastatic Cancers (SABR-COMET): A Randomised, Phase 2, Open-Label Trial. Lancet 2019, 393, 2051-2058. [CrossRef]

7. OECD Data: Selected indicators for Belgium. Available online: https://data.oecd.org/belgium.htm (accessed on 8 October 2018).

8. Siva, S.; Bressel, M.; Murphy, D.G.; Shaw, M.; Chander, S.; Violet, J.; Tai, K.H.; Udovicich, C.; Lim, A.; Selbie, L.; et al. Stereotactic Abative Body Radiotherapy (SABR) for Oligometastatic Prostate Cancer: A Prospective Clinical Trial. Eur. Urol. 2018, 74, 455-462. [CrossRef] 
9. De Bruycker, A.; Lambert, B.; Claeys, T.; Delrue, L.; Mbah, C.; De Meerleer, G.; Villeirs, G.; De Vos, F.; De Man, K.; Decaestecker, K.; et al. Prevalence and Prognosis of Low-Volume, Oligorecurrent, Hormone-Sensitive Prostate Cancer Amenable to Lesion Ablative Therapy. BJU Int. 2017, 120, 815-821. [CrossRef]

10. Neumann, P.J.; Cohen, J.T.; Weinstein, M.C. Updating Cost-Effectivenes-The Curious Resilience of the \$50,000-per-QALY Threshold. N. Engl. J. Med. 2014, 371, 796-797. [CrossRef]

11. Duchesne, G.M.; Woo, H.H.; Bassett, J.K.; Bowe, S.J.; D’Este, C.; Frydenberg, M.; King, M.; Ledwich, L.; Loblaw, A.; Malone, S.; et al. Timing of Androgen-Deprivation Therapy in Patients with Prostate Cancer with a Rising PSA (TROG 03.06 and VCOG PR 01-03 [TOAD]): A Randomised, Multicentre, Non-Blinded, Phase 3 Trial. Lancet Oncol. 2016, 17, 727-737. [CrossRef]

12. Mottet, N.; Bellmunt, J.; Bolla, M.; Briers, E.; Cumberbatch, M.G.; De Santis, M.; Fossati, N.; Gross, T.; Henry, A.; Joniau, S.; et al. EAU-ESTRO-ESUR-SIOG Guidelines on Prostate Cancer Part 1: Screening, Diagnosis, and Local Treatment with Curative Intent. Eur. Urol. 2017, 71, 618-629. [CrossRef] [PubMed]

13. Nguyen, P.L.; Alibhai, S.M.H.; Basaria, S.; D'Amico, A.V.; Kantoff, P.W.; Keating, N.L.; Penson, D.F.; Rosario, D.J.; Tombal, B.; Smith, M.R. Adverse Effects of Androgen Deprivation Therapy and Strategies to Mitigate Them. Eur. Urol. 2015, 67, 825-836. [CrossRef] [PubMed]

14. Bultijnck, R.; Surcel, C.; Ploussard, G.; Briganti, A.; De Visschere, P.; Fütterer, J.; Ghadjar, P.; Giannarini, G.; Isbarn, H.; Massard, C.; et al. Practice Patterns Compared with Evidence-Based Strategies for the Management of Androgen Deprivation Therapy-Induced Side Effects in Prostate Cancer Patients: Results of a European Web-Based Survey. Eur. Urol. Focus 2016, 2, 514-521. [CrossRef] [PubMed]

15. Stewart, S.T.; Lenert, L.; Bhatnagar, V.; Kaplan, R.M. Utilities for Prostate Cancer Health States in Men Aged 60 and Older. Med. Care 2005, 43, 347-355. [CrossRef] [PubMed]

16. Tengs, T.O.; Wallace, A. One Thousand Health-Related Quality-of-Life Estimates. Med. Care 2000, 38, 583-637. [CrossRef] [PubMed]

17. Cooperberg, M.R.; Ramakrishna, N.R.; Duff, S.B.; Hughes, K.E.; Sadownik, S.; Smith, J.A.; Tewari, A.K. Primary Treatments for Clinically Localised Prostate Cancer: A Comprehensive Lifetime Cost-Utility Analysis. BJU Int. 2013, 111, 437-450. [CrossRef] [PubMed]

18. Heijnsdijk, E.A.M.; Denham, D.; de Koning, H.J. The Cost-Effectiveness of Prostate Cancer Detection with the Use of Prostate Health Index. Value Health 2016, 19, 153-157. [CrossRef]

19. Center for the Evaluation of Value and Risk in Health. The Cost-Effectiveness Analysis Registry. 2018. Available online: https://cevr.tuftsmedicalcenter.org/databases/cea-registry (accessed on 2 February 2019).

20. RIZIV. Nomensoft. 2018. Available online: https://www.riziv.fgov.be/nl/toepassingen/Paginas/NomenSoft. aspx (accessed on 28 August 2018).

21. BCFI. Gecommentarieerd Geneesmiddelenrepertorium 2018. Available online: https://www.bcfi.be/ggr pdfs/GGR_NL_2018.pdf (accessed on 28 August 2018).

22. Cleemput, I.N.M.; Van de Sande, S.; Thiry, N. Belgische Richtlijnen Voor Economische Evaluaties en Budget Impact Analyses: Tweede Editie. 2012. Available online: https://kce.fgov.be/sites/default/files/atoms/files/ KCE_183A_economische_evaluaties_tweede_editie_0.pdf (accessed on 28 August 2018). (In Dutch).

23. STATBEL. Sterftetafels en Levensverwachting. 2019. Available online: https://statbel.fgov.be/nl/themas/ bevolking/sterfte-en-levensverwachting/sterftetafels-en-levensverwachting (accessed on 2 February 2019). (In Dutch).

24. Gezondheid Ze. Sterfte door prostaatkanker Brussels 2016. Available online: https://www.zorg-engezondheid.be/sterfte-door-prostaatkanker-2016 (accessed on 28 August 2018). (In Dutch).

25. Triggiani, L.; Alongi, F.; Buglione, M.; Detti, B.; Santoni, R.; Bruni, A.; Maranzano, E.; Lohr, F.; D’Angelillo, R.; Magli, A.; et al. Efficacy of Stereotactic Body Radiotherapy in Oligorecurrent and in Oligoprogressive Prostate Cancer: New Evidence from a Multicentric Study. Br. J. Cancer 2017, 116, 1520-1525. [CrossRef]

26. Decaestecker, K.; De Meerleer, G.; Lambert, B.; Delrue, L.; Fonteyne, V.; Claeys, T.; De Vos, F.; Huysse, W.; Hautekiet, A.; Maes, G.; et al. Repeated Stereotactic Body Radiotherapy for Oligometastatic Prostate Cancer Recurrence. Radiat. Oncol. 2014, 9, 135. [CrossRef]

27. Fossati, N.; Suardi, N.; Gandaglia, G.; Bravi, C.A.; Soligo, M.; Karnes, R.J.; Shariat, S.; Battaglia, A.; Everaerts, W.; Joniau, S.; et al. Identifying the Optimal Candidate for Salvage Lymph Node Dissection for Nodal Recurrence of Prostate Cancer: Results from a Large, Multi-Institutional Analysis. Eur. Urol. 2019, 75, 176-183. [CrossRef] 
28. Walker, L.M.; Tran, S.; Robinson, J.W. Luteinizing Hormone-Releasing Hormone Agonists: A Quick Reference for Prevalence Rates of Potential Adverse Effects. Clin. Genitourin. Cancer 2013, 11, 375-384. [CrossRef] [PubMed]

29. Bertram, M.Y.; Lauer, J.A.; De Joncheere, K.; Edejer, T.; Hutubessy, R.; Kieny, M.-P.; Hill, S.R. Cost-Effectiveness Thresholds: Pros and Cons. Bull. World Health Organ. 2016, 94, 925-930. [CrossRef] [PubMed]

30. Briggs, A.; Sculpher, M.; Claxton, K. Decision Modelling for Health Economic Evaluation,: 2006. Available online: https://www.herc.ox.ac.uk/downloads/decision-modelling-for-health-economic-evaluation (accessed on 3 October 2018).

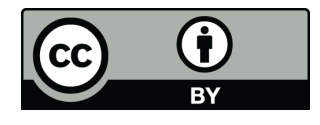

(C) 2020 by the authors. Licensee MDPI, Basel, Switzerland. This article is an open access article distributed under the terms and conditions of the Creative Commons Attribution (CC BY) license (http://creativecommons.org/licenses/by/4.0/). 